\title{
Autonomic neuropathy and transcutaneous oxymetry in diabetic lower extremities
}

\author{
L. Uccioli ${ }^{1}$, G. Monticone ${ }^{1,5}$, F. Russo ${ }^{2}$, F. Mormile ${ }^{3}$, L. Durola ${ }^{1}$, G. Mennuni ${ }^{4}$, F. Bergamo ${ }^{5}$, G. Menzinger ${ }^{1}$ \\ ${ }^{1}$ Cattedra di Endocrinologia, Università di Roma "Tor Vergata", Rome, Italy \\ 2 Cattedra di Semeiotica Chirurgica, Università di Roma "Tor Vergata", Rome, Italy \\ ${ }^{3}$ Istituto di Clinica Medica, Università Cattolica, Rome, Italy \\ ${ }^{4}$ Istituto di Clinica Neurologica, Università Cattolica, Rome, Italy \\ ${ }^{5}$ Istituto Dermopatico dell'Immacolata, Rome, Italy
}

Summary Transcutaneous oxygen tension is a useful method with which to assess the functional status of skin blood flow. The reduced values observed in diabetic patients have been interpreted as a consequence of peripheral vascular disease. However, diabetic patients show lower transcutaneous oxygen tension values than control subjects with equivalent degrees of peripheral vascular disease, suggesting that additional factors are involved. Since the autonomic nervous system influences peripheral circulation, we studied the relationship between autonomic neuropathy and foot transcutaneous oxymetry in non-insulindependent diabetic (NIDDM) patients without peripheral vascular disease. The following age-matched patients were selected and evaluated: control subjects, C, $(n=20)$, NIDDM patients without autonomic neuropathy, $\mathrm{D},(n=16)$ and with autonomic neuropathy, DN, $(n=20)$. All diabetic patients showed lower transcutaneous oxygen tension values than control subjects, while no differences were observed between the diabetic patients with and without autonomic neuropathy. In addition the saturation index that increases in the presence of autonomic neuropathy does not correlate with foot $\mathrm{Tc}_{\mathrm{PO}}$. In conclusion autonomic neuropathy does not influence foot $\mathrm{Tc} \mathrm{PO}_{2}$ and therefore it is unlikely that it contributes to development of foot lesions during induction of foot skin ischaemia. [Diabetologia (1994) 37: 1051-1055]

Key words Diabetic autonomic neuropathy, transcutaneous oxymetry, galvanic skin response, blood oxygen content, diabetic foot.
There is evidence to show that diabetes mellitus causes a reduction in limb TcPO $2[1,2]$. Tc $P \mathrm{O}_{2}$ is directly related to skin oxygen delivery and the degree of hypoxia has been correlated with clinical symptoms of peripheral ischaemia [3]. However, diabetes causes a reduction in $\operatorname{limb} \mathrm{Tc} P \mathrm{O}_{2}$ beyond that which can be accounted for by large-vessel occlusive arterial disease alone [4].

Received: 21 January 1994

and in revised form: 1 June 1994

Corresponding author: Dr. L. Uccioli, c/o Complesso Integrato Columbus, via Pineta Sacchetti, 506, I-00168 Rome, Italy

Abbreviations: NIDDM, Non-insulin-dependent diabetes mellitus; $\mathrm{Tc} \mathrm{PO}_{2}$, transcutaneous oxymetry; A-V, arterio-venous shunts; PVD, peripheral vascular disease; $\mathrm{HbA}_{1 \mathrm{c}}$, glycated haemoglobin; SI, saturation index.
The autonomic nervous system plays an important role in regulating peripheral blood flow with sympathetic nerve fibers regulating flow through their action on the A-V shunts physiologically dedicated to thermal regulation [5]. The failure of sympathetic control results in a vasodilatation with increased flow through the A-V shunts and therefore an increased total peripheral blood flow [6]. This could be associated with a reduced flow in nutritional capillaries (capillary steal) and explain the coexistence of increased peripheral skin blood flow and of cutaneous ulceration in patients with autonomic neuropathy [7]. According to this line of reasoning the low $\mathrm{Tc} \mathrm{PO}_{2}$ values observed in diabetic patients might be the consequence of peripheral autonomic neuropathy. Therefore, our aim was to evaluate the influence of peripheral autonomic neuropathy on $\mathrm{Tc} \mathrm{PO}_{2}$. 


\section{Patients and methods}

Patients. This study was approved by the Ethical Committee of the University of Rome "Tor Vergata" and informed consent was obtained from all subjects. After a thorough interview to eliminate any potential interfering neurological condition (alcohol addiction, thyroid disease, lumbar root disease, etc.) 56 subjects were enrolled in the study. In order to exclude significant peripheral vascular disease or major vascular complications, the patients were evaluated by Doppler ultrasound technique and only those showing an ankle/brachial index between 0.9 and 1.1 were included in the study.

All the patients were non-smokers, normotensive and none were taking drugs affecting blood pressure. The subjects were distributed into three groups: group C: 20 control subjects; group D: 16 NIDDM patients without autonomic neuropathy; group DN: 20 NIDDM patients with autonomic neuropathy. Diabetic patients were included in the group with neuropathy in the presence of at least two abnormal cardiovascular tests for autonomic function and absent galvanic skin response (see below), and in the group without neuropathy in the presence of normal values for all cardiovascular tests and present galvanic skin response. This test was chosen because it has been already used to investigate the function of small unmyelinated sympathetic fibers in the limbs of diabetic subjects $[8,9]$. Clinical characteristics of the subjects are given in Table 1. The following tests were applied to all the subjects:

1] Transcutaneous oxymetry $\left(\mathrm{TcPO} \mathrm{O}_{2}\right)$ : $\mathrm{Tc} \mathrm{PO}_{2}$ (Kontron, Roche inc., Everett, Mass., USA) values were recorded for $1 \mathrm{~h}$ and a half on the chest and on the dorsum of each foot, with the patient resting in the supine position. Recordings were made at an electrode temperature of $44.1^{\circ} \mathrm{C}$ [10]. Room temperature was maintained between $24-26^{\circ} \mathrm{C}$.

2] Arterial and venous partial pressure of oxygen $\left(\mathrm{PaO}_{2}, \mathrm{PvO}_{2}\right)$ and oxygen content: determined by the autoanalyzer radiometer (ABL 330 with OSM 3 Hemoximeter Copenhagen, Denmark). Arterial blood was drawn from the radial artery and venous blood from a superficial vein on the dorsum of each foot. The percentage of oxygen saturation in the peripheral veins was calculated by applying the following formula: saturation index (SI) $=\mathrm{PvO}_{2} / \mathrm{PaO}_{2} \%$ [11]

3] Cardiovascular autonomic function: assessed by four cardiovascular tests: heart rate variation on deep breathing, on lying to standing and during the Valsalva manoeuver, blood pressure fall on standing. Tests were always performed in the morning and evaluated according to standard procedures [12].

4] Galvanic skin response (GSR): GSR measurements were recorded from the sole of the foot, after a sensory stimulus was applied to the controlateral foot. The patients with a clear biphasic response were classified as GSR present, the patients without any response were classified as GSR absent, all others being excluded [13].

5] Vibratory perception threshold(VPT): vibratory sensitivity was measured with a Biothesiometer (Biomedical Instrument Co., Newbury, Ohio, USA) applying the vibrating probe to the dorsal surface of the great toe and to the external malleolus of both sides.Three determinations were made at each site and the mean values were calculated [14].

Glycated haemoglobin $\left(\mathrm{HbA}_{1 \mathrm{c}}\right)$ (minicolumn technique: BIORAD, Richmond, Calif., USA) and albuminuria micro (Micral test Boeringher Mannheim Gmbh, Mannheim, Ger-
Table 1. General characteristics of the patients

\begin{tabular}{llll}
\hline Group & $\begin{array}{l}\text { Age } \\
\text { (years) }\end{array}$ & $\begin{array}{l}\text { Diabetes duration } \\
\text { (years) }\end{array}$ & $\mathrm{HbA}_{1 \mathrm{c}}$ \\
\hline $\begin{array}{l}\text { Control } \\
(n=20)\end{array}$ & $51.5 \pm 3.4$ & & \\
$\begin{array}{l}\text { Diabetic } \\
(n=16)\end{array}$ & $51.2 \pm 1.6$ & $9.5 \pm 1.9$ & $7.3 \pm 3.4$ \\
$\begin{array}{l}\text { Diabetic } \\
\text { neuropathic } \\
(n=20)\end{array}$ & $56.2 \pm 1.4$ & $13.4 \pm 2.6$ & $7.9 \pm 0.33$ \\
\hline
\end{tabular}

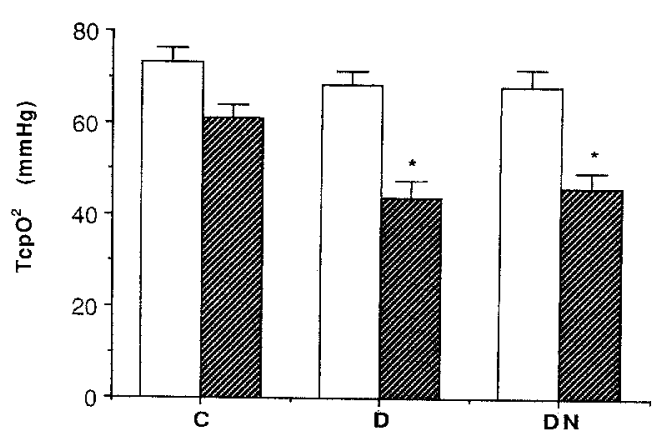

Fig. 1. Foot $\mathrm{Tc} P \mathrm{O}_{2}$ was significantly reduced in the diabetic (D) and diabetic neuropathic (DN) groups compared to the control (C) group, $\left({ }^{*} p<0.001\right)$, while chest $\mathrm{Tc}_{\mathrm{PO}} \mathrm{O}_{2}$ was similar in the three groups. $\square$, chest,

many) and macro (Albustix, Ames-Miles Division, Elkhart, Ind., USA) were recorded on the day of the study. An eye examination was performed not more than 3 months before the study.

\section{Statistical analysis}

All results are expressed as mean \pm SEM. Statistics were calculated using a computer (Macintosh Apple) programmed with a standard statistical package (Statview). Analysis of variance, multivariate analysis and linear regression were performed as indicated with $p$ values less than 0.05 considered significant.

\section{Results}

Chest $\mathrm{Tc} \mathrm{PO}_{2}$ was similar in all groups; both diabetic groups had values for foot $\mathrm{Tc} P \mathrm{O}_{2}$ lower than those observed in group $\mathrm{C}(p<0.001)$ (Fig. 1), but there were no differences between these two groups. In contról subjects there was a correlation between chest and foot $\mathrm{TcPO}_{2}$ values and age $(r=0.5$; $p=0.02 ; r=0.6, p=0.003$, respectively). In diabetic patients while chest $\mathrm{Tc} \mathrm{PO}_{2}$ values correlated with age $(r=0.6 ; p=0.0001)$, foot $\mathrm{Tc}_{\mathrm{CO}} \mathrm{O}_{2}$ values did not. There was no correlation between chest and foot Tc $\mathrm{PO}_{2}$ and the duration of disease. $\mathrm{PaO}_{2}$ was similar in all groups with a mean value of $87.9 \pm 15.4$. The SI values were significantly higher in group DN than in 


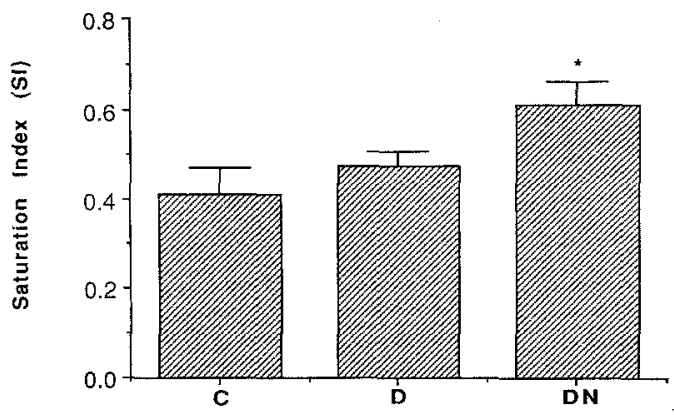

Fig. 2. Saturation index $\left(\mathrm{PvO}_{2} / \mathrm{PaO}_{2}\right)$ was significantly increased in the diabetic neuropathic (DN) group compared to the control (C) and diabetic (D) groups $(* p<0.01)$

groups $\mathrm{C}$ and $\mathrm{D}$ but there were no differences between groups $\mathrm{C}$ and D (Fig. 2). There was also no correlation between SI and $\mathrm{Tc} P \mathrm{O}_{2}$ within each group or when all groups were pooled together; SI showed a correlation with duration of disease $(r=0.462$, $p=0.002)$.

Table 2 shows the cardiovascular autonomic tests and Table 3 the characteristics of peripheral somatic neuropathy, retinopathy and nephropathy for the three groups.

\section{Discussion}

Theoretical and experimental analysis of the transcutaneous oxygen measurement indicates that $\mathrm{Tc} P \mathrm{O}_{2}$ is a useful method with which to assess the functional status of skin blood flow $[15,16]$. Various investigators have already correlated lower limb $\mathrm{Tc} P \mathrm{O}_{2}$ with pedal artery pressure $[17,18]$, signs and symptoms of occlusive arterial disease $[19,20]$ and prognosis for the healing of amputation sites in patients with foot ulcers [21-23]. Therefore, $\mathrm{Tc} P \mathrm{O}_{2}$ is currently being used as a powerful tool for investigation of PVD [24-26].
Several authors have observed a reduction in foot $\mathrm{Tc}_{\mathrm{CO}}$ in diabetic patients $[1,27]$ and have interpreted these data to be a consequence of PVD. However, Rooke and Osmundson [4] have observed that diabetic patients show lower $\mathrm{Tc} \mathrm{PO}_{2}$ values than nondiabetic patients with equivalent degrees of PVD. Therefore, foot $\mathrm{Tc} P \mathrm{O}_{2}$ in diabetic patients might be influenced by additional factors, such as autonomic neuropathy, cutaneous microangiopathy etc. Our work was focused on the influence of autonomic neuropathy on foot $\mathrm{Tc} P \mathrm{O}_{2}$.

The autonomic nervous system, supplying the arterioles and the A-V shunts with sympathetic adrenergic fibers, directly influences peripheral circulation [28-33]. The consequence of a sympathetic dysfunction is a vasodilatation and an increased flow through the A-V shunts [34], which results in an increased oxygen content in the foot venous blood and therefore in an increased SI $[35,36]$. Related to this a "capillary steal" phenomenon has been hypothesized [7]. This could explain the reduced foot $\mathrm{Tc} P \mathrm{O}_{2}$ values in diabetic patients without PVD. According to this hypothesis, foot $\mathrm{Tc} P \mathrm{O}_{2}$ should be reduced in patients with autonomic neuropathy. However, in our experience foot $\mathrm{Tc} \mathrm{PO}_{2}$ was reduced both in diabetic patients with and without autonomic neuropathy. Furthermore, no correlation between SI and foot $\mathrm{Tc}_{\mathrm{PO}}$ values was found. All these observations suggest that sympathetic failure does not influence foot $\mathrm{Tc} P \mathrm{O}_{2}$.

The increased oxygen content in the foot venous blood in the group of diabetic patients with autonomic neuropathy is in accordance with the hypothesis of an increased blood flow throughout the A-V shunts in patients with peripheral neuropathy $[6,7$, $11,36]$, but at the same time our data suggest that a "capillary steal" phenomenon is unlikely, and in any case it does not influence foot $\mathrm{Tc} P \mathrm{O}_{2}$. This observation accords with the data from Flynn et al. [37] show-

Table 2. Cardiovascular tests for autonomic function

\begin{tabular}{llllc}
\hline Group & E: I & LS & VR & PH \\
\hline Control $(n=20)$ & $1.465 \pm 0.072$ & $1.275 \pm 0.003$ & $1.85 \pm 0.023$ & $4.5 \pm 0.028$ \\
Diabetic $(n=16)$ & $1.403 \pm 0.073$ & $1.287 \pm 0.093$ & $2.06 \pm 0.128$ & $7 \pm 2.98$ \\
Diabetic neuropathic $(n=20)$ & $1.193 \pm 0.031^{\mathrm{a}, \mathrm{b}}$ & $1.081 \pm 0.028^{\mathrm{a}, \mathrm{b}}$ & $1.459 \pm 0.101^{\mathrm{a}, \mathrm{b}}$ & $15.55 \pm 5.38$ \\
\hline
\end{tabular}

E: I, Expiration - inspiration ratio; LS, lying to standing; VR, Valsalva ratio; PH, postural hypotension. ${ }^{\text {a }}$ Diabetic neuropathic VS Control $p<0.05$; ${ }^{b}$ diabetic neuropathic VS diabetic $p<0.05$

Table 3. Characteristics of peripheral neuropathy, retinopathy and nephropathy

\begin{tabular}{llll}
\hline & VPT $(\mathrm{mV})$ & Retinopathy No/B/P & Nephropathy No/Mi/Ma \\
\hline Control $(n=20)$ & $11.33 \pm 2$ & & \\
Diabetic $(n=16)$ & $19.79 \pm 4.5$ & $5 / 8 / 3$ & $8 / 8 / 0$ \\
Diabetic neuropathic $(n=20)$ & $36.24 \pm 2.7^{\mathrm{a}, \mathrm{b}}$ & $1 / 7 / 12$ & $6 / 6 / 8$ \\
\hline
\end{tabular}

VPT, Vibration perception threshold; retinopathy: $\mathrm{N}=\mathrm{no}, \mathrm{B}=$ background, $\mathrm{P}=$ proliferative; nephropathy: $\mathrm{N}=$ no, $\mathrm{Mi}=$ microalbuminuria, $\mathrm{Ma}=$ macroalbuminuria. ${ }^{\mathrm{a}}$ Diabetic nephropathy VS control $p<0.01$; ${ }^{\mathrm{b}}$ Diabetic nephropathic VS diabet-
ic $p<0.05$ 
ing that capillary flow is maintained in diabetic patients with autonomic neuropathy. Therefore, it seems unlikely that autonomic neuropathy may contribute to the development of foot lesions throughout the induction of foot skin ischaemia. If we exclude the influence of autonomic neuropathy on foot $\mathrm{Tc} \mathrm{PO}_{2}$ other conditions such as cutaneous microvascular disorders and barriers to oxygen diffusion could be considered to explain the reduced foot $\mathrm{Tc} \mathrm{PO}_{2}$ values observed in diabetic patients. Although our work was not designed to explore these other hypotheses, our data may nevertheless throw some light on these points.

Although thickening of the capillary basement membrane is a common finding in diabetes [38, 39], there is no clear evidence of skin capillary narrowing $[40,41]$ or occlusion $[37,42,43]$. According to our observations, the influence of structural microangiopathy on foot $\mathrm{Tc} \mathrm{PO}_{2}$ is unlikely, because patients with different degrees of microangiopathic complications in other areas (retinopathy and nephropathy) show equivalent foot $\mathrm{Tc} P \mathrm{O}_{2}$ values.

The thickening of dermal collagen with increased cross-linking from non-enzymatic glycation could result in a "barrier" to oxygen diffusion [44]. These changes are related to aging [4] and in diabetic patients to the quality of glycaemic control and duration of disease [45]. While this mechanism could explain the relationship between chest $\mathrm{Tc} \mathrm{PO}_{2}$ and age in control subjects and diabetic patients, it does not explain why foot $\mathrm{Tc} \mathrm{PO}_{2}$ in diabetic subjects does not correlate with age and duration of disease.

None of the hypotheses discussed so far seem to explain the reduced foot $\mathrm{Tc} \mathrm{PO}_{2}$ in diabetic patients. An additional hypothesis includes a role for functional abnormalities of the microcirculation [46]. These are considerable in diabetes in general, and not necessarily confined to subjects with obvious neuropathy $[47,48]$. According to this hypothesis Breuer et al. [2] observed reduced foot $\mathrm{Tc} P \mathrm{O}_{2}$ values even in diabetic patients with a diabetes duration of less than 1 year and free from any detectable microangiopathic complication.

In conclusion, while our data confirm the low foot $\mathrm{Tc} \mathrm{PO}_{2}$ values observed in diabetic patients, the clinical impact of this is still unknown. We do not know whether the reduced foot $\mathrm{Tc} P \mathrm{O}_{2}$ values observed in the absence of peripheral vascular disease justify the increased susceptibility to foot ulceration observed in diabetic patients. In addition we do not understand the mechanism underlying this phenomenon. Our work was able to exclude a direct role for systemic autonomic neuropathy but does not give information about the local autoregulation mechanisms that, theoretically, could have a role. In our opinion further research in this area is needed to fully understand this finding.

\section{References}

1. Railton R, Newman P, Hislop J, Harrower ADB (1983) Reduced transcutaneous oxygen tension and impaired vascular response in type 1 (insulin-dependent) diabetes. Diabetologia 25:340-342

2. Breuer HWM, Breuer J, Berger M (1988) Transcutaneous oxygen pressure measurements in type 1 diabetic patients for early detection of functional diabetic microangiopathy. Eur J Clin Invest 18:454-459

3. Hauser CJ, Klein SR, Mehringer CM, Appel P, Shoemaker WC (1984) Superiority of transcutaneous oxymetry in noninvasive vascular diagnosis in patients with diabetes. Arch Surg 119:690-694

4. Rooke TW, Osmundson PJ (1990) The influence of age, sex, smoking, and diabetes on lower limb transcutaneous oxygen tension in patients with arterial occlusive disease. Arch Intern Med 150:129-132

5. Coffman JD (1972) Total and nutritional blood flow in the finger. Clin Sci 42:243-250

6. Watkins PJ, Edmonds ME (1983) Sympathetic nerve failure in diabetes. Diabetologia 25:73-77

7. Ward JD, Boulton AJM, Simms JM, Sandler DA, Knight G (1983) Venous distension in the diabetic neuropathic foot (physical sign of arteriovenous shunting). J R Soc Med 76:1011-1014

8. Maselli RA, Jaspan JA, Soliven BC, Green AJ, Spire JP, Arnason BGW (1989) Comparison of sympathetic skin response with quantitative sudomotor axon reflex test in diabetic neuropathy. Muscle Nerve 12:420-423

9. Macleod AF, Smith SA, Cowell T, Richardson PR, Sonksen PH (1991) Non cardiac autonomic test in diabetes: use of the galvanic skin response. Diabet Med 8 [Suppl]:S67-S70

10. Dowd CSE, Linge K, Bentley G (1983) Measurement of transcutaneous oxygen pressure in normal and ischaemic skin. J Bone Joint Surg Br 65:79-83

11. Boulton AJM, Scarpello JHB, Ward JD (1981) Venous oxygenation in the diabetic neuropathic foot: evidence of arteriovenous shunting. Diabetologia 22:6-8

12. Ewing DJ, Martyn CN, Young RJ, Clarke BF (1985) The value of cardiovascular autonomic function tests: 10 years experience in diabetes. Diabetes Care 8:491-498

13. Pestell RG, Kirsner RLG, Best JD (1991) Validation and evaluation of test for sympathetic cholinergic function in diabetes mellitus. Diabetes 40:867-872

14. Dyck PJ, Karnes J, O'Brien PC, Zimmermann IR (1984) Detection thresholds of cutaneous sensation. In: Dyck PJ, Thomas PK, Lambert EH, Bunge RD (eds) Peripheral neuropathy. W.B. Saunders Company, Philadelphia $p$ 1103

15. Wyss CR, Matsen FA, King RV, Simmons CW, Burgess EM (1981) Dependence of transcutaneous oxygen tension on local arteriovenous pressure gradient in normal subjects. Clin Sci 60:499-506

16. Wyss CR, Matsen FA, Simmons CW, Burgess EM (1984) Transcutaneous oxygen tension measurements on limbs of diabetic and non diabetic patients with peripheral vascular disease. Surgery 95 [3]:339-345

17. Ohgi S, Ito K, Mori T (1981) Quantitative evaluation of the skin circulation in ischemic legs by transcutaneous measurements of oxygen tension. Angiology 32:833-839

18. Clyne CA, Ryan J, Webster J, Chant ADB (1982) Oxygen tension on the skin of ischemic legs. Am J Surg 143:315-318

19. Rooke TW, Hollier LH, Osmundson PJ (1987) The influence of sympathetic nerves on transcutaneous oxygen tension in normal and ischemic lower extremities. Angiology $38: 400-410$ 
L. Uccioli et al.: Foot $\mathrm{Tc} P \mathrm{O}_{2}$ and autonomic neuropathy

20. Ratliff DA, Clyne CAC, Chant ADB, Webster JHH (1984) Prediction of amputation wound healing: the role of transcutaneous PO2 assessment. Br J Surg 71:219-222

21. Katsamouris A, Brewster DC, Megerman J, Cina C, Darling RC, Abbott WM (1984) Transcutaneous oxygen tension in selection of amputation level. Am J Surg 147:510 517

22. Osmundson PJ, Rooke TW, Hallet JW (1988) Effect of arterial revascularization on transcutaneous oxygen tension of the ischaemic extremity. Mayo Clin Proc 63:897-902

23. Benscoter JL, Gerber A, Friedberg J (1984) Transcutaneous oxygen measurement as noninvasive indicator of level of tissue healing in patients with peripheral vascular disease and projected amputation. J Am Osteopath Assoc $83: 560-574$

24. Knote G, Bohmart H (1977) Determination of the viability of skin regions in danger of necrosis by means of transcutaneous polarographic measurement of oxygen pressure. Fortschritte Der Medizin 95:640-644

25. Wyss CR, Robertson C, Love SJ, Harrington RM, Matsen FA (1987) Relationship between transcutaneous oxygen tension, ankle blood pressure, and clinical outcome of vascular surgery in diabetic and non-diabetic patients. Surgery 101 [1]:56-62

26. Hauser CJ, Stanley RK, Meheringer CM, Appel P, Shoemaker WC (1984) Assessment of perfusion in the diabetic foot regional transcutaneous oxymetry. Diabetes 33:527531

27. Gaylarde PM, Fonseca VA, Llewellyng G, Sarkany I, Thomas PK, Dandona P (1988) Transcutaneous oxygen tension in legs and feet of diabetic patients. Diabetes 37:714716

28. Mellander S, Johansson B (1968) Control of resistance, exchange and capacitance functions in the peripheral circulation. Pharm Rev 20:117-196

29. Delius WK, Hagbarth E, Hongell A, Walkin BG (1972) Manoeuvres affecting sympathetic outflow in human skin nerves. Acta Physiol Scand 84:177-186

30. Lee JS, Visscher MB (1957) Microscopic studies of skin blood vessels in relation to sympathetic nerve stimulation. Am J Physiol 90:37-40

31. Schwinghamer JM, Grega GJ, Haddy FJ (1970) Skin and muscle circulatory responses during prolonged hypovolemia. Am J Physiol 219:318-326

32. Celander O, Folkow B (1953) A comparison of the sympathetic vasomotor fibre control of the vessels within the skin and the muscle. Acta Physiol Scand 29:241-250

33. Mark AL, Abboud FM, Schimd PG, Heistad DD, Mayer HE (1972) Differences in direct effects of adrenergic stimuli on coronary, cutaneous and muscular vessels. J Clin Invest 51:279-287
34. Edmonds ME, Roberts VC, Watkins PJ (1982) Blood flow in the diabetic neuropathic foot. Diabetologia 22:9-15

35. Kida Y, Kashiwagi A, Nishio Y, Kodama M, Abe N, Shigeta $Y$ (1988) Is difference of arterial and venous oxygen content a possible marker for diabetic foot? Diabetes Care 6:515-516

36. Uccioli L, Mancini L, Giordano A et al. (1992) Lower limb arteriovenous shunts, autonomic neuropathy and diabetic foot. Diab Res Clin Pract 16:123-130

37. Flynn MD, Edmonds ME, Tooke JE, Watkins PJ (1988) Direct measurement of capillary blood flow in the diabetic neuropathic foot. Diabetologia 31:652-656

38. Braverman IM, Yen AK (1984) Ultrastructural abnormalities of the microvascular and elastic fibers in the skin of juvenile diabetes. J Invest Dermatol 82:270-274

39. Cox NH, McCruden D, McQueen A, Jones JK, Ong-Tone L, Finlay AY, Frier BM (1987) Histological findings in clinically normal skin of patients with insulin-dependent diabetes. Clin Exp Dermatol 12:250-255

40. Banson BB, Lacy PE (1964) Diabetic microangiopathy in human toes: with emphasis on the ultrastructural change in dermal capillaries. Am J Pathol 45:41-58

41. Chazan BI, Balodimos MC, Lavin RL, Koncz L (1970) Capillaries of the nailfold of the toe in diabetes mellitus. Microvasc Res 2:501-507

42. Conrad MCM (1981) Contribution of large and small vessel disease to severe ischaemia of the lower extremities in diabetics and non-diabetics. Vascular Diagn Ther 2:17-23.

43. Rayman G, Hassan AAK, Tooke JE (1986) Blood flow in the skin of the foot related to posture in diabetes mellitus. BMJ 293:87-90

44. Buckingam BA, Uitto J, Sandborg C, Keens T, Kaufman F, Landing B (1981) Scleroderma-like syndrome and non-enzymatic glycosylation of collagen in children with poorly controlled insulin-dependent diabetes. Paediatr Res 15:626 (Abstract)

45. Monnier VM, Vishwanath V, Frank KE, Elmets CA, Dauchot P, Kohn AR (1986) Relationship between complications of type 1 diabetes mellitus and collagen linked fluorescence. N Engl J Med 314:403-407

46. Ditzel J (1968) Functional microangiopathy in diabetes mellitus. Diabetes 17:388-397

47. Ward JD (1987) Vascular and neural damage in the diabetic foot. In: Andreani D, Crepaldi G, Di Mario V, Pozza G (eds) Diabetic complications: early diagnosis and treatment. Wiley,Chicester, pp 177-183

48. Tooke JE (1993) Methodologies used in the study of the microcirculation in diabetes mellitus. Diab Metab Rev 9 (1):57-70 